\title{
Design Cycle Period Management
}

\author{
Bahram Soltanmohammad \\ Sharif University of Technology \\ IRAN
}

\section{Introduction}

As competition increases and new technologies emerge, the civil aerospace industries need relatively better appropriate frameworks to guarantee their success. Efficient and close interactions among all disciplines involved in the aircraft design process from manufacturing, to the flight testing, are essential for improving the quality of the product. However, such necessities generally lead to a lengthy design cycle. Because of this, a strategy for cycle time reduction (CTR) must always be available. This process is called Integrated Airframe Design (IAD), (AGARD Report 814). A proper CTR leads to lessened costs which is essential in surviving a competition since time, cost and quality are three parameters that are normally used to evaluate the efficiency of a design process (Ullman, 2003).

Researches on CTR could be categorized into four branches: 1- reducing engineering man hours; 2- reducing tooling hours; 3- reducing testing activities 4- implementing process and information technologies(NASA/CR-2001-210658).

In the design process of complex systems, similar to that of an airplane, engineering tasks are either: coupled, sequential, parallel or compound ones. The design process of such a product is naturally in an iterative form (Eppinger \& Whitney, 1994). In the scientific modeling of a design process, iterations are considered as specific features to be addressed (NSF, 1996). Iterations of a design process could be divided into two types (Browning, 1998): 1. Intentional iterations, performed between any two disciplines which help converging toward a satisfying solution.

2. Unintentional iterations that occur due to arrival of new information into the design process.

In this chapter we concentrate on the first type.

The very existence of iterations in the design process is the primary source of the increase in the development cycle time and its associated cost. Several studies have documented iteration effects as the driver of the overall development cycle time (Clark, 1993, Eisenhardt, 1995). Therefore, one expects that managing iterations and keeping them to a minimum leads to a more efficient design process. In this chapter, we investigate reducing man-hours by improving iteration characteristics. According to Smith and Eppinger there are two main strategies in increasing the speed of the design process: 1- faster execution of iterations; 2reducing the number of necessary iterations in the design process (Smith \& Eppinger, 1997). Extensive studies have been carried out by different researchers for either strategy. For example, the information flow model in designing tasks and distinguishing their cyclic 
loops has been investigated by Steward in the form of a design structure matrix (DSM) (Steward, 1981). Eppinger continued this work and the information cycle in a design process was modeled in a clearer fashion while different strategies for the process management were investigated (Eppinger and Whitney, 1994). Browning developed a new methodology to understand product development cost, schedule, and performance (Browning, 1998). These works could be assessed from different points of views such as; presenting a systematic method for "Cycle Time Reduction" that allows each design topic to be analyzed according to its specific features. This approach allows managers to involve contractors in designing a big system in an efficient manner. One might also consider the approach in the broader subject of "Subcontracting". The fact that the WTM Concept could suggest what part of the project would be a good candidate for subcontracting, does not necessarily means that such implementation is an economic solution as well. That is WTM deals only with controlling the duration of the project and not the financial aspect of it. This chapter however, focuses on controlling iterations by means of iteration dynamic order reduction or tear-out "Controlling Features" (C.F.s) of a design process. To show how the new approach could be implemented, we use the WTM of a GENERAL AVAITION(G.A.) AIRPLANE.

Following an introduction, we briefly discuss the application of Design Structure Matrix (DSM) to describe the so called Work Transformation Matrix (WTM). Then, we describe the main idea of the current chapter and how it is used to reduce the dynamic order of the iterations in a typical design process. Finally, we present a case study together with discussions on a G. A. airplane design process, and discuss the results.

\section{Design process modeling by means of (DSM)}

Most designers believe that the first step in design process management is creating a comprehensive model which contains all the design tasks and their relationship. According to Yassine and Falkenburg, and Chelst; one of the main problems in the design process is the existence of the information cycles in tasks (Yassine et al., 1999). Any information cycle means the information interchanges among different disciplines in the design process. According to Pahl and Bietz the reason for the very existence of information cycles is related to the complexity in disciplines of the coupled design parameters (Pahl\& Bietz, 1996); Using a comprehensive model one could break the information cycles in suitable points, thus the complexity of the design process will be reduced. A comprehensive model should contain two characteristics:

1. Ability to identify information cycles

2. Ability to identify effective dynamic elements or suitable points to break information cycles

The DSM method decomposes a more general design problem into separate tasks and while representing the relation among tasks as $\mathrm{X}$; it provides a systematic way to analyze the design process structure. Each of the tasks is placed in rows and columns of a square matrix and the relationship among the tasks shown by the $\mathbf{X}$ marks. The $\mathbf{X}$ marks along each row show the input data which is needed for carrying out the tasks of that row. The $\mathbf{X}$ marks along each column show the output data which is supplied by that column task for other tasks. As a result the $\mathbf{X}$ marks above the diagonal show the feedback information and the $\mathbf{X}$ marks under the diagonal show the feed forward information; thus, the coupled part of the design process is then readily available (Figure -1). 


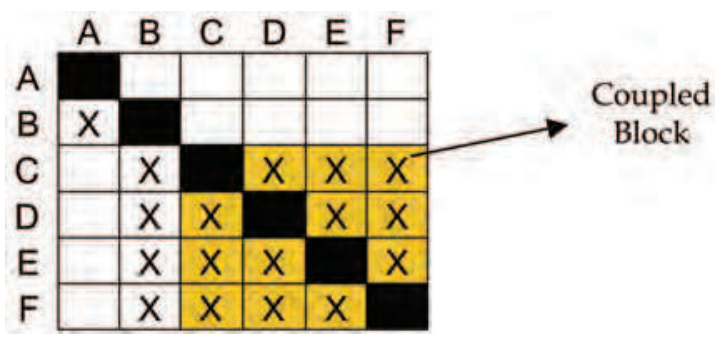

Fig. 1. Sample DSM Representing Coupled Tasks

Thus DSM provides the aforementioned characteristics in a systematic way. In order to study of the behavior of iterations, a numerical DSM, called the Work Transformation Matrix (WTM), can be used (Smith\&Eppinger 1997). Works done by the mentioned researchers suggest that three assumptions enable us to use linear algebra to analyze a WTM; as follows:

1. All iterations are done parallel.

2. The rework done is a linear function of the work done in the previous step.

3. The relationships among the tasks do not change in time.

In this Chapter, we accept the aforementioned assumptions as the basis of the work; however, from a theoretical point of view, assumption number (1) applies to a big design organization where all engineering disciplines are available. This assumption basically means that members of engineering teams are fixed and that they work simultaneously on the same design problem. Also, this assumption gets closer to the reality wherever "Concurrent Engineering" is exercised.

Assuming "time of conducting an iteration" to be a linear function of previous ones, is generally not a precise assumption. However, due to an engineer's cognitive learning, it is believed that as the design process proceeds, performing iterations become both simpler and faster. Considering this, a linear decrease in conducting iterations would be somehow meaningful; as we would expect with a linear decrease in work associated with iterations. It is worth noting however, that at the moment there is no other approach to quantitatively model the nature of iterations. Besides linear approximation, one might think of a bi-linear model or tri-linear one. Nevertheless, different case studies by the authors show that such models would not effectively change the behavior of iterations (Soltanmohammad, PhD Thesis, 2007). One of the factors that influence the validity of the linear model is the very existence of some technological jumps that might occur during the execution of the project. In such cases, one might use a new approach based on "Time Dependent Complexity" (TDC) of coupled design parameters (Suh, 2003). In general, the second and third assumptions will be correct if we are not dealing with too many iterations. Moreover, since assumption number (3) does not support the effect of the so called "Learning Curve" in an organization it must be used very carefully.

Based on what was described earlier, one can describe any iteration as a vector $\mathbf{u}_{\mathrm{t}}$ with dimension " $n$ " where " $n$ " is the number of coupled design tasks, relation (1). Each entries of the iteration vector shows the iteration job done after the $t^{\text {th }}$ stage of iteration. If matrix $A$ is a part of WTM, which contains the data about the dependency intensity of tasks to one another, then according to Smith and Eppinger the work vector and total work vector $U$ are (Smith and Eppinger, 1997): 


$$
\begin{gathered}
u_{t+1}=A \cdot u_{t} \\
U=\sum_{t=0}^{M} u_{t}=\left(\sum_{t=0}^{M} A^{t}\right) u_{0}
\end{gathered}
$$

That $\mathrm{t}$ is the iteration stage, $\mathrm{u}$ is the work vector, and $\mathrm{M}$ is the total number of iterations and $u_{0}$ is the initial work vector, that, all entries of $\mathrm{u}_{0}$ are equal to 1.0. After decomposing matrix $\mathrm{A}$, one might derive a relationship between $\mathrm{U}$ and eigenstructure of $\mathrm{A}$ as follows:

$$
U=S \cdot(I-\Lambda)^{-1} \cdot S^{-1} u_{0}
$$

Where $S$ and $\Lambda$ are eigenvectors and diagonal eigenvalues of matrix A respectively. According to (3), the dynamics (structure) of a design process is related to the time needed for conducting that design and from there to the nature of the eigenvalues and eigenvectors of the WTM. According to (3) the eigenvalues which are real and positive values close to unity, have a major role in the work vector $U$ and in contrary role of the negative eigenvalues which are close to -1.0 are not important. The effect of complex eigenvalues is established by their real parts. If the real part is positive and near 1 , then the eigenvalue plays an important role; otherwise it does not. Based on Perron-Frobenius theory, the biggest eigenvalue of a matrix like WTM, where all entries are non-negative, is always a real and positive number (Minc, 1988). In this way, the design mode associated with the largest eigenvalue can be selected as the most dominant design mode. This design mode has an eigenvector which is strictly positive and relatively larger elements of the eigenvector determine the contribution of the corresponding tasks to the dominant design mode. From a mathematical point of view, one might interpret the entries of this eigenvector to be more effective in the dominant design mode. In this way the C.F.s of the design process are identified as the tasks inside the most dominant design mode which have relatively greater contribution in convergence/divergence of iterations.

By thoroughly examining the eigenvector entries, one can understands the C.F.s of the design process (Smith\& Eppinger 1997). It can be stated that the number and characteristics of iterations are function of the C.F.s of a design process. Unlike what we interpret from Smith and Eppinger's work, we might say that the contribution of each task and the number of effective tasks are different in generating iterations. The differences are related to the nature of the WTM.

Based on the mentioned reasoning, C.F.s can be selected by following the simple relation:

$$
\frac{V_{i}}{V_{\max }}>K_{d}
$$

$V_{i}: i^{\text {th }}$ Entry of dominant mode eigenvector

$V_{\max }$ : Maximum entry of dominant mode eigenvector

$K_{d}$ : A decision parameter based on the designers experience (usually 0.5)

If (4) holds, then $V_{i}$ is a C.F. Obviously, C.F.s each design processes differs, of course, this adapt with designers experiences and observations.

To optimize a DSM, one might take advantage of four mathematical operations as follows: 
1. Partitioning: Partitioning is the process of manipulating (i.e. reordering) the DSM rows and columns such that the new DSM arrangement does not contain any feedback marks, that is, in a lower triangular form. In engineering systems, it is highly unlikely that a simple row and column manipulation will result in a lower triangular form. Therefore, the objective changes from eliminating the feedback marks to moving them as close as possible to the diagonal.

2. Clustering: The goal of clustering is to find subsets of DSM elements (clusters or modules) that are mutually exclusive or minimally interacting subsets. Clusters absorb most of the interactions while links between separating clusters are eliminated or minimized.

3. Banding: Banding is the addition of alternating light and dark bands to a DSM to show independent, parallel or concurrent activities.

4. Tearing: Tearing is the process of choosing a group of $(X)$ (feedback marks) inside the information cycles in such a way that eliminating them from the matrix, changes that matrix into a lower triangular one. The $\mathrm{X}$ signs which are eliminated from the matrix are called "tear tasks".

In this chapter, we use tearing to reduce cycle time in a systematic manner. Therefore, we can further explain the tearing operation.

The procedure to eliminate some tasks from iteration, known as tearing, is explained by different authors. Based on works published by; (Austin et al.,1999); tearing is the process of choosing a group of feedback marks inside the information cycles in such a way that eliminates them from a DSM to render a lower triangular one. The tasks which are eliminated from the existing DSM are called "tear tasks". Knowing that tear tasks are equivalent to the assumptions needed to start a design process, no further estimation is needed for conducting the design process (Yassine, 1999). According to Austin and Yassine, although there is no optimum method available, there are two main criteria for the tearing process (Austin \& Yassine, 1999):

1. Confine tears to the smallest blocks along the diagonal.

2. Minimize number of tear tasks.

Steward suggests tearing on the basis of breaking the effective information cycles. He uses shunt Diagrams for this purpose (Steward 1981). However, since analyzing the diagram of the tear tasks becomes too complicated, the method proves to be unsuitable for big design organizations. Roger, suggests a heuristic process for selecting the tasks in order to minimize the information cycles (Roger 1989). Kusiak and Wang explored all tasks involved in producing iterations and their occurrence frequency (Kusiak \& Wang, 1993). They suggested tear those with a relatively greater occurrence frequency. Yassine presents the so called "Quality criteria" for tearing via a degree of sensitivity, uncertainty, and a dependency of tasks (Yassine, 1999).

All tearing criteria suggested so far have been proven inefficient; as they are either too complex to implement, or highly dependent on previous experiments and individual innovations taken from managers who need to have some type of international participation. In this chapter we reduce dynamic order of the design process, to minimize the design cycle period. To do this, in first step, the C.F.s of a given design process, must be identified. This tends to be a systematic approach that relies basically on the understanding of the design process itself; rather than previous experiences or personal skills. It is necessary to mentioned, reduce dynamic order of the design process also known as 
"Tearing". This new approach tends to help less-experiencing designers control the whole design as well as its associated factors of time and cost.

Next section of this chapter, further explained about the suggested approach to reduce dynamic order of the design process.

\section{Controlling of iterations by reducing DSM dynamic order}

In the design process of multi-disciplinary systems, such as aircrafts, the design task can be decomposed into sub-tasks based on the nature of the subsystem and the engineering discipline involved. Naturally, all disciplines tend to solve their own problems in an optimum manner. However, due to the coupled nature of the design parameters (Figure-2), optimizing individual sub-tasks would not necessarily lead to an optimized overall design.

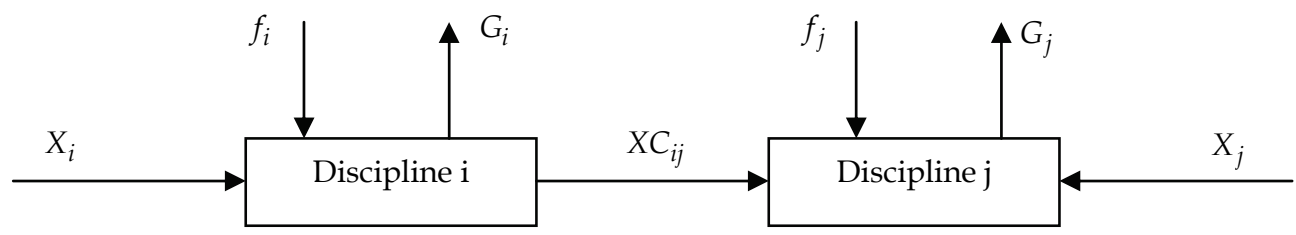

Fig. 2. Schematic Representation of Coupled Design Problem

Based on Hacker with DSPi, any design problem could be mathematically expressed as a systematic procedure to find a set of design parameters while optimizing function fi, where (Hacker, 1996):

Goals: Optimize $\mathrm{f}$; fi $=\mathrm{F}\left(\mathrm{Xnc}_{\mathrm{i}}, \mathrm{Xc}_{\mathrm{i}}\right)$

Constraints: $\mathrm{Gi}$; Gi $=\mathrm{G}\left(\mathrm{Xnc}_{\mathrm{i}}, \mathrm{Xc}_{\mathrm{i}}\right)$

fi :Objective function in discipline $i$

G i : Constraint function in discipline i

$\mathbf{X i}$ : Design parameters of discipline $\mathrm{i}$

Xnc i : Non - Coupled Design parameters of discipline i

Xci : Coupled Design parameters of discipline i

DSPi : Decision Support Problem of discipline i

Obviously, changing any of the coupled design parameters between either two disciplines will change the objective and other constrictive functions accordingly. That is, as soon as a change is applied to any coupled design parameters by one of the disciplines, other disciplines must re-iterate their process as a response to the imposed change. This, in turn, has effect on other coupled parameters. This process continues until all disciplines reach to a satisfactory solution based on their individual objectives. The satisfactory solution described based on Figure -3 . This Figure illustrates the difference between the range of selecting a coupled design parameter in two disciplines $i$ and $j$. At the beginning of the iteration process, both disciplines designated by $i$ and $j$ might select $X C_{i i_{0}}$ as a coupled design parameter. Once iterations proceed each discipline receives information from others that might lead to changing the coupled design parameter. These changes should establish a pattern moving toward a common area (Figure -3). Once each discipline selects the coupled design parameter at the common area iteration will terminate, meaning that cost function 
and constraint of each discipline DSP is satisfied. It must be note that work done on DSP change as all disciplines cost functions and constraints change, at each stage of iteration. According to Shearer, Murphy and Richradson in dynamic systems at least one variable varies in time (Shearer, Murphy and Richradson, 1971). Then, one might treat iteration process as a dynamic system as work done at each stage varies in time. According to Figure3 , any iteration while dealing with WTM could be treated as a time dependent complexity between two disciplines; where complexity is defined as a function of common range between task $i$ and task $j$ (Suh 2003). It is necessary to mention that probability density on Figure-3 follows a uniform distribution.

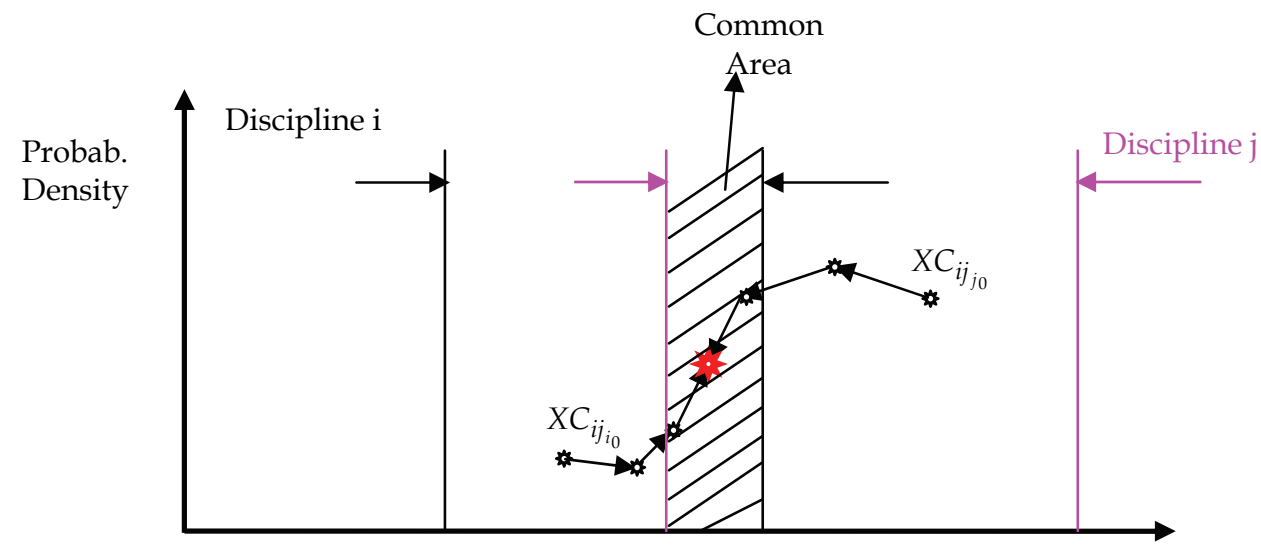

Coupled Design Parameter $X C_{i j}$

Fig. 3. Complexity between two coupled tasks

Considering a work vector modeled by WTM as:

$$
u_{t+1}=A u_{t}
$$

With $t$, as the iteration stage, above relation could rewrite as:

$\mathrm{U}(\mathrm{t}+1)=\mathrm{Au}(\mathrm{t}) \quad(\mathrm{a})$

The equation describing the so called discrete- linear- time invariant dynamic system becomes:

$\mathrm{X}(\mathrm{k}+1)=\mathrm{G} \cdot \mathrm{X}(\mathrm{k}) \quad(\mathrm{b})$;

Where $G$ represents the State Transition Matrix that shows the nature of the dynamic system. Here, we present a systematic approach to improving the dynamic behavior of the iterations process through modifications in the state transition matrix. There are two general approaches for such improvement (Soltanmohammad, PhD Thesis, 2007):

1. Improving $[\mathrm{A}]$, by improving its entries through injecting information to some tasks

2. Improving $[\mathrm{A}]$ by reducing its dynamic order (eliminating rows \&columns).

In this chapter, we use the second approach, knowing that entries of [A] are greater or equal to zero:

$$
\mathrm{A}=\left[a_{i j}\right] \quad a_{i j} \geq 0
$$


Assuming $\rho(A)$ is the spectral radius or the largest eigenvalue of $[\mathrm{A}]$; where $[\mathrm{A}]$ is a nonnegative matrix, then according to Minc, spectral radius of any sub-matrix of $[\mathrm{A}]$ are smaller than spectral radius of [A] itself (Minc, 1988). That is, if any associated row and column of [A] is eliminated (tearing), then the remaining matrix has a spectral radius which is smaller than $[A]$ itself. This is interpreted as increasing iteration speed or iteration convergence rate. In order to minimize the spectral radius of [A], element(s) that have the highest influence on the dynamics must first be identified. These are in fact C.F.s with relatively greater values. Thus, we perform tearing (system dynamic reduction) based on the order of magniuted of the C.F.s This mathematical process requires a successive conversion of work vector $u$ together with the state transition matrix $[\mathrm{A}]$ to $\mathrm{u}^{\prime}$ and $\mathrm{A}^{\prime}$, with the following equations:

$$
\begin{aligned}
& U=\left(\sum_{t=0}^{M} A^{t}\right) u_{0} \\
& U^{\prime}=\left(\sum_{t=0}^{M^{\prime}} A^{\prime t}\right) u_{0}^{\prime}
\end{aligned}
$$

Since $A^{\prime}$ is in fact a principle sub matrix of $[\mathrm{A}]$, then, according to (Minc, 1988):

$$
\begin{aligned}
& \rho(A)>\rho\left(A^{\prime}\right) \\
& \rho(A) \equiv \max |\lambda| \quad \lambda \in \sigma(A)
\end{aligned}
$$

In which, $\sigma(\mathrm{A})$ is a set representing all the distinct eigenvalues of [A] (spectrum of $[\mathrm{A}]$ ). Regardless of what mathematical proof offers, we present a real case scenario for a typical General Aviation airplane design process to demonstrate the effectiveness of the new approach. Of course, it must be note that tearing some tasks would not lead to ignoring them. In reality it simply means converting a coupled block to a smaller block or smaller blocks and a block containing tear-out tasks (Figure-4)

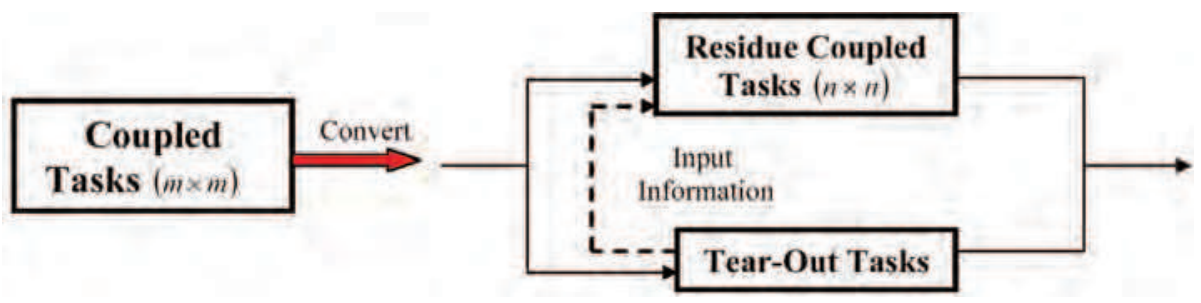

Fig. 4. Architecture of coupled part of design process after iteration dynamic reduction $(\mathrm{m}>\mathrm{n})$

The generic blocks of Figure-4 could be performing in a semi-parallel way. That is, the tearout C.F.s block provides necessary input information for residue coupled tasks block(s), in this way, the blocks can run parallel. Tear-out C.F.s block can provide necessary input information for other blocks by Rational Reaction Set (RRS); (a-Kurt Hacker \& Kemper Lewis, 1998; b-Wei Chen \& Kemper Lewis, 1999). 


\section{Case studies and results}

To show the merits of the new approach, we describe how it is applied to an actual G.A. airplane design process. In this study, dynamic order of the G.A. airplane design process is reduced using five different scenarios. The selected scenarios allow us to investigate the influence of tearing C.F.s on iteration convergence speed. Since G.A. airplane is in fact an actual aircraft going through the certification and enhancement process, case studies might help validate the proposed approach. The execution algorithm starts by establishing G.A. airplane DSM. We demonstrate a simplified version of such DSM (Table 1). Applying partitioning to identify the design cycles (Table 2). Next, we establish WTM and identify its coupled part through interviewing engineers participating in the project (Table 3). Dominant modes and therefore candidate C.F.s, to implement "tearing" are identified by the eigenstructure analysis of the WTM (Table 4). Table-5 provides the selected scenarios to reduce the dynamic order of the design iteration of G.A. airplane.

For having the ability to compare the results both with and without the application of new methods and for undergoing different scenarios while applying it, authors use the following set of criteria:

\begin{tabular}{|c|c|c|c|c|c|c|c|c|c|c|c|c|c|c|c|c|}
\hline Task Name & & $1 \mid 2$ & 3 & 4 & 5 & & 7 & 9 & & 10 & 11 & 12 & 13 & 14 & 15 & 1 \\
\hline Decide on General Design Requirements & 1 & & & & & & & & & & & & & & & \\
\hline Performance Sizing & 2 & 1 & & & & & & & & & & & & & & \\
\hline Select Preliminary Configuration Alternative & 3 & \begin{tabular}{l|l}
1 & 1 \\
\end{tabular} & & & & & 1 & & 1 & & 1 & & & & & \\
\hline Mathematical Surface Models & 4 & & 1 & & 1 & & 1 & & & & & & & & & \\
\hline Aerodynamics Calculation & 5 & 1 & & 1 & & & & & & & & & & & & \\
\hline Preliminary Structural Arrangement & 6 & 1 & & 1 & & & & & & 1 & & & & 1 & 1 & \\
\hline Prepare for cabin \& Fuselage Design & 7 & 1 & 1 & & & & & & & & & & & & & \\
\hline Develop Structural Design Conditions & 8 & 1 & & & & 1 & & & & & & & & & & \\
\hline Integration Propulsion & 9 & \begin{tabular}{l|l}
1 & 1 \\
\end{tabular} & & & & & 1 & & & & & & & & & \\
\hline Perform Preliminary Weight \& Balance & 10 & & & & & & 1 & & 1 & & & & & 1 & & \\
\hline Stability \& Control Analysis & 11 & 1 & & & 1 & & & & & 1 & & & & & & \\
\hline V-n Diagram & 12 & & & & 1 & & & 1 & & 1 & & & 1 & & & \\
\hline Internal Load Distributions & 13 & & & & & & & 1 & & 1 & & 1 & & & & \\
\hline Structural Analysis & 14 & 1 & & & & & & & 1 & & & 1 & 1 & & & \\
\hline Preliminary Production Program & 15 & 1 & & & & & 1 & & 1 & & & & & 1 & & \\
\hline Concept Selection & 16 & \begin{tabular}{l|l}
1 & 1 \\
\end{tabular} & 1 & 1 & 1 & 1 & 1 & $1]$ & 1 & 1 & 1 & 1 & 1 & 1 & 1 & \\
\hline
\end{tabular}

Table 1. G.A. airplane DSM

1. Convergence Improvement: The degree of increase in Convergence Speed (CS) is defined as:

$$
C S=\frac{\lambda_{1_{B T}}-\lambda_{1_{A T}}}{\lambda_{1_{B T}}}
$$

Where $\lambda_{1_{A T}}, \lambda_{1_{B T}}$ are respectively the most dominant mode eigenvalues before and after tearing. 


\begin{tabular}{|c|c|c|c|c|c|c|c|c|c|c|c|c|c|c|c|c|}
\hline Task Name & & 1 & 2 & 3 & $\overline{4}$ & 5 & 6 & 7 & \begin{tabular}{l|l}
8 & 5 \\
\end{tabular} & 10 & 11 & 12 & 13 & 14 & & 16 \\
\hline Decide on General Design Requirements & 1 & & & & & & & & & & & & & & & \\
\hline Performance Sizing & 2 & 1 & & & & & & & & & & & & & & \\
\hline Select Preliminary Configuration Alternative & 3 & 1 & 1 & & & & & 1 & 1 & & 1 & & & & & \\
\hline Mathematical Surface Models & 4 & & & 1 & & 1 & & 1 & & & & & & & & \\
\hline Aerodynamics Calculation & 5 & 1 & & & 1 & & & & & & & & & & & \\
\hline Preliminary Structural Arrangement & 6 & 1 & & & 1 & & & & & 1 & & & & 1 & 1 & \\
\hline Prepare for cabin \& Fuselage Design & 7 & 1 & & 1 & & & & & & & & & & & & \\
\hline Develop Structural Design Conditions & 8 & 1 & & & & & 1 & & & & & & & & & \\
\hline Integration Propulsion & 9 & 1 & 1 & & & & & 1 & & & & & & & & \\
\hline Perform Preliminary Weight \& Balance & 10 & & & & & & & 1 & 1 & & & & & 1 & & \\
\hline Stability \& Control Analysis & 11 & 1 & & & & 1 & & & 1 & 1 & & & & & & \\
\hline V-n Diagram & 12 & & & & & 1 & & & 1 & 1 & & & 1 & & & \\
\hline Internal Load Distributions & 13 & & & & & & & & 1 & 1 & & 1 & & & & \\
\hline Structural Analysis & 14 & 1 & & & & & & & 11 & & & 1 & 1 & & & \\
\hline Preliminary Production Program & 15 & 1 & & & & & & 1 & 1 & & & & & 1 & & \\
\hline Concept Selection & 16 & 1 & 1 & 1 & 1 & 1 & 1 & & 111 & $\begin{array}{lll}1 & 1 \\
\end{array}$ & 1 & 1 & 1 & 1 & 1 & \\
\hline
\end{tabular}

Table 2. Partitioned G.A. airplane DSM

\begin{tabular}{|c|c|c|c|c|c|c|c|c|c|c|c|c|c|c|}
\hline Tasks & No. & 3 & 4 & 5 & 6 & 7 & 8 & 9 & 10 & 11 & 12 & 13 & 14 & 15 \\
\hline Select Preliminary Configuration Alternative & 3 & 0 & 0 & 0 & 0 & 0.3 & 0 & 0.3 & 0 & 0.2 & 0 & 0 & 0 & 0 \\
\hline Mathematical Surface Models & 4 & 1 & 0 & 0.4 & 0 & 0.2 & 0 & 0 & 0 & 0 & 0 & 0 & 0 & 0 \\
\hline Aerodynamics Calculation & 5 & 0 & 0.5 & 0 & 0 & 0 & 0 & 0 & 0 & 0 & 0 & 0 & 0 & 0 \\
\hline Preliminary Structural Arrangement & 6 & 0 & 0.5 & 0 & 0 & 0 & 0 & 0 & 0.1 & 0 & 0 & 0 & 0.3 & 0.1 \\
\hline Prepare for cabin \& Fuselage Design & 7 & 0.2 & 0 & 0 & 0 & 0 & 0 & 0 & 0 & 0 & 0 & 0 & 0 & 0 \\
\hline Develop Structural Design Conditions & 8 & 0 & 0 & 0 & 0.2 & 0 & 0 & 0 & 0 & 0 & 0 & 0 & 0 & 0 \\
\hline Integration Propulsion & 9 & 0 & 0 & 0 & 0 & 0.4 & 0 & 0 & 0 & 0 & 0 & 0 & 0 & 0 \\
\hline Perform Preliminary Weight \& Balance & 10 & 0 & 0 & 0 & 0 & 0.3 & 0 & 0.4 & 0 & 0 & 0 & 0 & 0.5 & 0 \\
\hline Stability \& Control Analysis & 11 & 0 & 0 & 0.7 & 0 & 0 & 0 & 0.5 & 0.7 & 0 & 0 & 0 & 0 & 0 \\
\hline V-n Diagram & 12 & 0 & 0 & 0.1 & 0 & 0 & 0.2 & 0 & 0.1 & 0 & 0 & 0.4 & 0 & 0 \\
\hline Internal Load Distributions & 13 & 0 & 0 & 0 & 0 & 0 & 0.5 & 0 & 0.5 & 0 & 0.3 & 0 & 0 & 0 \\
\hline Structural Analysis & 14 & 0 & 0 & 0 & 0 & 0 & 0.5 & 0.2 & 0 & 0 & 0.1 & 0.1 & 0 & 0 \\
\hline Preliminary Production Program & 15 & 0 & 0 & 0 & 0.2 & 0.1 & 0 & 0.1 & 0 & 0 & 0 & 0 & 0.1 & 0 \\
\hline
\end{tabular}

Table 3. WTM of the G.A. airplane Project Showing Coupled part

2. Coupled part Reduction: This criterion presents the effect of tearing most important C.F.s on work volume of design process coupled part and is calculated as follows:

$$
\begin{aligned}
& C W \equiv S^{-1} U_{0} \cdot\left(\sum \text { All Coupled Tasks }\right) ; C W \text { :Couple Task Weight } \\
& (C P R)=\frac{(C W)_{\text {Before Tearing }}-(C W)_{\text {After Tearing }}}{\text { Tear Task Weight }}
\end{aligned}
$$

CPR:Couple Part Reduction 


\begin{tabular}{|c|c|c|}
\hline Task Name & Eigenvector Elements & Task No \\
\hline V-n Diagram & 0.283 & 12 \\
\hline Aerodynamics Calculation & 0.302 & 5 \\
\hline Internal Load Distributions & 0.322 & 13 \\
\hline Preliminary Structural Arrangement & 0.424 & 6 \\
\hline Mathematical Surface Models & 0.425 & 4 \\
\hline Stability \& Control Analysis & 0.482 & 11 \\
\hline
\end{tabular}

Table 4. Controlling Feature of the most dominant design mode before tearing

\begin{tabular}{|c|c|c|}
\hline Scenarios & Tear-out Tasks & Tasks No. \\
\hline \multirow{3}{*}{ Case-1 } & Preliminary Structural Arrangement & 6 \\
& Mathematical Surface Models & 4 \\
& Stability \& Control Analysis & 11 \\
\hline Case-2 & Mathematical Surface Models & 4 \\
& Stability \& Control Analysis & 11 \\
\hline Case-3 & Stability \& Control Analysis & 11 \\
\hline Case-4 & Mathematical Surface Models & 4 \\
\hline Case-5 & Preliminary Structural Arrangement & 6 \\
\hline
\end{tabular}

Table 5. Design Scenarios under Study for tearing

3. Number of Controlling Features: No of C.F.s

4. Total Work: Total work is the sum of entries of the work vector and is computed based on (3)

5. Rank Improvement: Resulting improvement in the rank of each mode is the fifth criterion and is calculated by:

$$
\frac{\left(\left(\frac{1}{1-\lambda_{1_{B T}}}\right)-\left(\frac{1}{1-\lambda_{1_{A T}}}\right)\right)}{\left(\frac{1}{1-\lambda_{1_{B T}}}\right)}
$$

6. Controlling Features Weight: Controlling Feature weight is computed from multiplying the sum of C.F. vector entries in $S^{-1} U_{0}$ of the same Mode.

It is interesting to note that there would be no difference in results while applying coefficient of $S^{-1} U_{0}$ instead of ones associated with $(I-\Lambda)^{-1} S^{-1} U_{0}$. Since:

$$
(I-\Lambda)^{-1}=\left[\begin{array}{cccc}
\frac{1}{1-\lambda_{1}} & 0 & \cdots & 0 \\
\vdots & \ddots & & \vdots \\
\vdots & & \ddots & \vdots \\
0 & \cdots & \cdots & \frac{1}{1-\lambda_{n}}
\end{array}\right]
$$


Therefore, the first entry of $(I-\Lambda)^{-1} S^{-1} U_{0}$, that is used as a coefficient associated with the first mode, is:

$$
\left[(I-\Lambda)^{-1} S^{-1} U_{0}\right]_{1}=\frac{1}{1-\lambda_{1}}\left[S^{-1} U_{0}\right]_{1}
$$

The difference between $\left[(I-\Lambda)^{-1} S^{-1} U_{0}\right]_{1}$ and $\left[S^{-1} U_{0}\right]_{1}$ is in fact $\frac{1}{1-\lambda_{1}}$ can not influence the results of comparison.

After the eigenstructure analysis of table-3, the eigenvalue of the most dominant mode of G.A. airplane design process is $\lambda=0.700$ and the C.F.s of the most dominant mode are shown in table (4). Considering all tasks of table (4) which are the C.F.s of the most dominant mode, one can deduce that the most important part of the G.A. airplane design process are Stability \& Control analysis (task 11), Mathematical Surface Models (task 4), structural design \& analysis (tasks 13,12 and 6 ) and Aerodynamic Calculation (task 5), in all of which four disciplines are involved. These problems are the main problems of the G.A. airplane design process. The reduction of dynamic order of the design iteration of G.A. airplane design process is now investigated under five different scenarios (Table (5)).

Case-1: In this case, the three most efficient C.F.s, tasks 11, 4, 6, are torn. After tearing and repartitioning, the task table of the G.A. airplane will become as demonstrated in Table- 6 . This table shows a new design process in which coupled parts are broken into two. The larger block has four coupled tasks while the other has three. We consider the former as the major block and the latter as the minor block. The relationships in the new arrangement of the blocks are shown in Figure-5. The C.F.s of the most dominant design mode resulting from this new arrangement are shown, after tearing, in Table-7.

\begin{tabular}{|c|c|c|c|c|c|}
\hline Tasks & No. & 10 & 12 & 13 & 14 \\
\hline Perform Preliminary Weight \& Balance & 10 & 0 & 0 & 0 & 0.5 \\
\hline V-n Diagram & 12 & 0.1 & 0 & 0.4 & 0 \\
\hline Internal Load Distributions & 13 & 0.5 & 0.3 & 0 & 0 \\
\hline Structural Analysis & 14 & 0 & 0.1 & 0.1 & 0 \\
\hline
\end{tabular}

Table 6. The WTM after partitioning and tearing (First case major block)

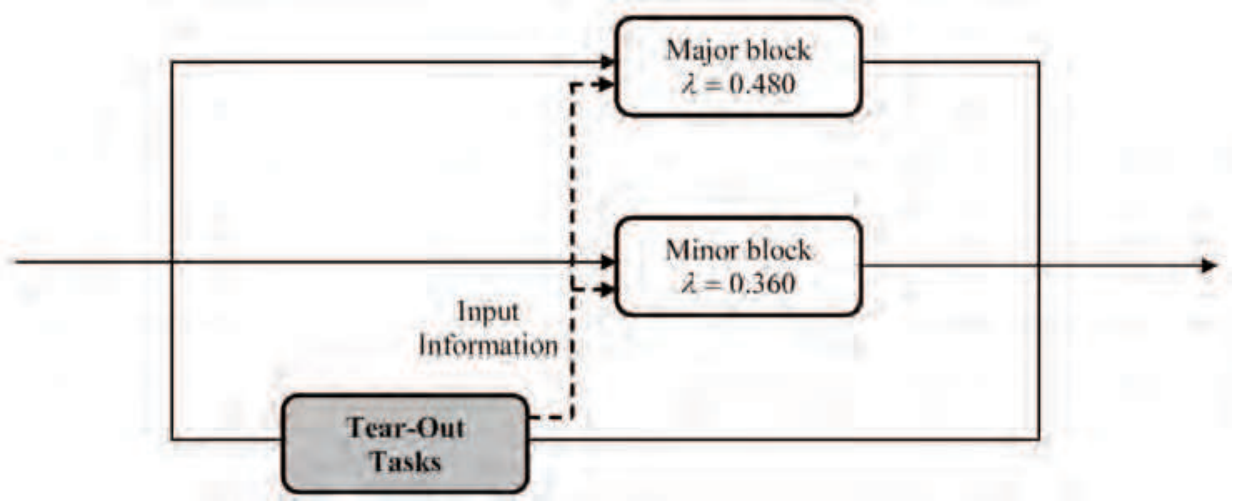

Fig. 5. Architecture of the major and minor blocks with tear-out tasks at (Case-1) 
It is necessary to mention that the presented characteristics in Table-20 relating to the major block, because of the eigenvalues of the major block, are greater than the minor block.

Case - 2: In this case the two tasks, 4 and 11, will be considered as tear-outs. Table (9) shows the results of the tearing. Here, we have two coupled blocks: a major block in which there are six coupled tasks and a minor block in which there are three coupled tasks. The C.F.s of the most dominant design mode are shown after tearing in Table-10. Also, Figure-6 demonstrates the arrangement discussed in the preceding case.

\begin{tabular}{|c|c|c|}
\hline Task Name & Eigenvector Elements & Task No \\
\hline V-n Diagram & 0.622 & 12 \\
\hline Internal Load Distributions & 0.679 & 13 \\
\hline
\end{tabular}

Table 7. C.F.s of the most dominant design mode after tearing (First case)

\begin{tabular}{|c|c|c|c|c|}
\hline Tasks & No. & 3 & 7 & 9 \\
\hline Select Preliminary Configuration Alternative & 3 & & 0.3 & 0.3 \\
\hline Prepare for cabin \& Fuselage Design & 7 & 0.2 & & 0 \\
\hline Integration Propulsion & 9 & 0 & 0.4 & \\
\hline
\end{tabular}

Table 8. The WTM after partitioning and tearing (First case minor block)

\begin{tabular}{|c|c|c|c|c|c|c|c|}
\hline Tasks & No. & 6 & 8 & 10 & 12 & 13 & 14 \\
\hline Preliminary Structural Arrangement & 6 & 0 & 0 & 0.1 & 0 & 0 & 0.3 \\
\hline Develop Structural Design Conditions & 8 & 0.2 & 0 & 0 & 0 & 0 & 0 \\
\hline Perform Preliminary Weight \& Balance & 10 & 0 & 0 & 0 & 0 & 0 & 0.5 \\
\hline V-n Diagram & 12 & 0 & 0.2 & 0.1 & 0 & 0.4 & 0 \\
\hline Internal Load Distributions & 13 & 0 & 0.5 & 0.5 & 0.3 & 0 & 0 \\
\hline Structural Analysis & 14 & 0 & 0.5 & 0 & 0.1 & 0.1 & 0 \\
\hline
\end{tabular}

Table 9. The WTM after partitioning and tearing (Case-2 major block)

\begin{tabular}{|c|c|c|}
\hline Task Name & Eigenvector Elements & Task No \\
\hline V-n Diagram & 0.575 & 12 \\
\hline Internal Load Distributions & 0.662 & 13 \\
\hline
\end{tabular}

Table 10. The C.F.s of the most dominant design mode after tearing (Case-2)

Case - 3: In this case, only the most effective C.F. will be torn. After the tearing and repartitioning, the design process changes into Tables 12, 14 and 15. The major block (Table12), has seven coupled tasks. There are also two minor blocks: block-a (Table-14) and block-b (Table-15). The new arrangement of the blocks and tear-out task are shown in the following Figure-7. The C.F.s of the most dominant design mode after tearing is also shown in Table (13). 


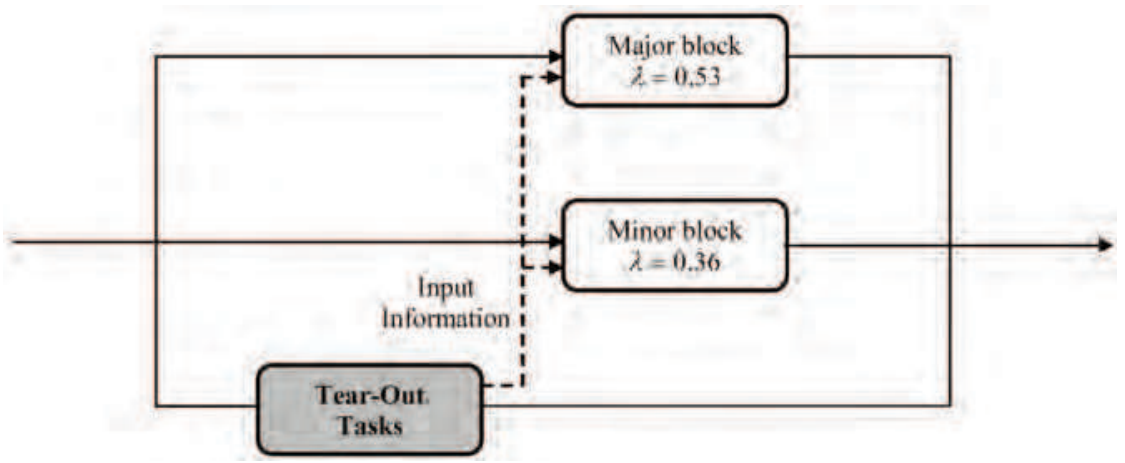

Fig. 6. Architecture of major and minor blocks and tear-out tasks at Case-2

\begin{tabular}{|c|c|c|c|c|}
\hline Tasks & No. & 3 & 7 & 9 \\
\hline Select Preliminary Configuration Alternative & 3 & & 0.3 & 0.3 \\
\hline Prepare for cabin \& Fuselage Design & 7 & 0.2 & & 0 \\
\hline Integration Propulsion & 9 & 0 & 0.4 & \\
\hline
\end{tabular}

Table 11. The WTM after partitioning and tearing (second case minor block)

\begin{tabular}{|c|c|c|c|c|c|c|c|c|}
\hline Tasks & No. & 6 & 8 & 10 & 12 & 13 & 14 & 15 \\
\hline Preliminary Structural Arrangement & 6 & 0 & 0 & 0.1 & 0 & 0 & 0.3 & 0.1 \\
\hline Develop Structural Design Conditions & 8 & 0.2 & 0 & 0 & 0 & 0 & 0 & 0 \\
\hline Perform Preliminary Weight \& Balance & 10 & 0 & 0 & 0 & 0 & 0 & 0.5 & 0 \\
\hline V-n Diagram & 12 & 0 & 0.2 & 0.1 & 0 & 0.4 & 0 & 0 \\
\hline Internal Load Distributions & 13 & 0 & 0.5 & 0.5 & 0.3 & 0 & 0 & 0 \\
\hline Structural Analysis & 14 & 0 & 0.5 & 0 & 0.1 & 0.1 & 0 & 0 \\
\hline Preliminary Production Program & 15 & 0.2 & 0 & 0 & 0 & 0 & 0.1 & 0 \\
\hline
\end{tabular}

Table 12. The WTM after partitioning and tearing (Third case major block)

\begin{tabular}{|c|c|c|}
\hline Task Name & Eigenvector Elements & Task No \\
\hline V-n Diagram & 0.562 & 12 \\
\hline Internal Load Distributions & 0.650 & 13 \\
\hline
\end{tabular}

Table 13. C.F.s of the most dominant mode C.F.s after tearing (Third case).

\begin{tabular}{|c|c|c|c|c|}
\hline Tasks & No. & 3 & 7 & 9 \\
\hline Select Preliminary Configuration Alternative & 3 & & 0.3 & 0.3 \\
\hline Prepare for cabin \& Fuselage Design & 7 & 0.2 & & 0 \\
\hline Integration Propulsion & 9 & 0 & 0.4 & \\
\hline
\end{tabular}

Table 14. The WTM after partitioning and tearing (Third case minor block-a) 


\begin{tabular}{|c|c|c|c|}
\hline Tasks & No. & 4 & 5 \\
\hline Mathematical Surface Models & 4 & & 0.4 \\
\hline Aerodynamics Calculation & 5 & 0.5 & \\
\hline
\end{tabular}

Table 15. The WTM after partitioning and tearing (Third case minor block-b)

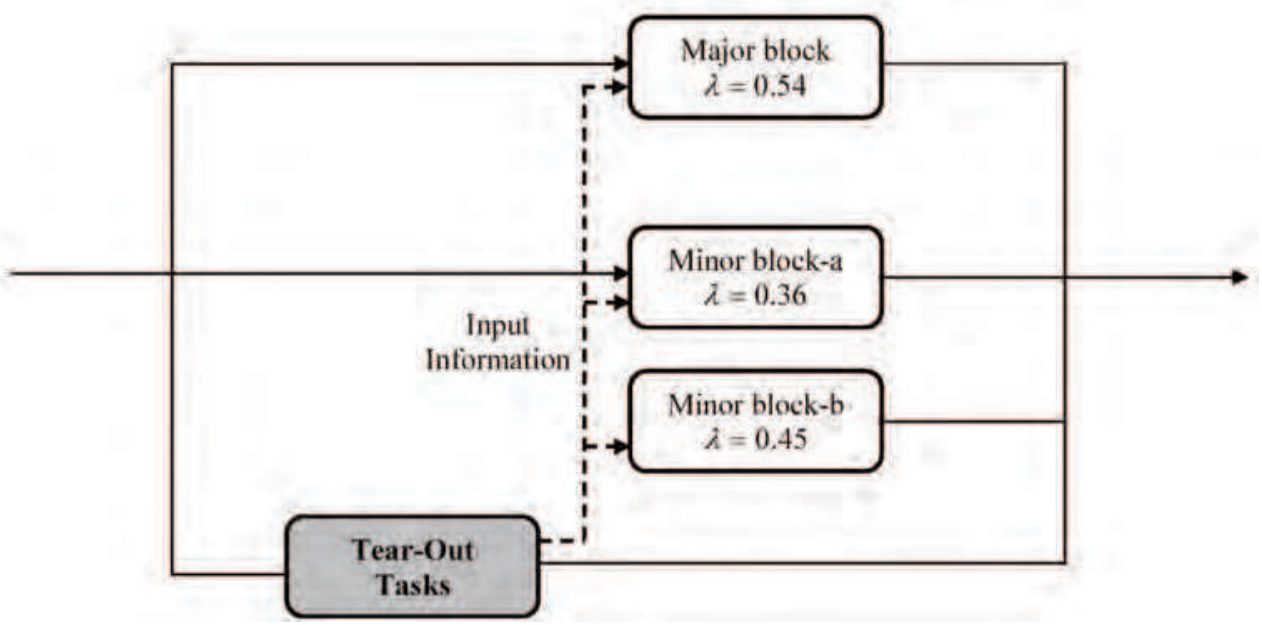

Fig. 7. Architecture of major and minor blocks and tear-out tasks at Case-3

Case - 4: In this case, only Task 4 will be torn. After the tearing and repartitioning of the WTM, the table of the tasks of the G.A. airplane will change into Table (16). This table shows that after tear-out, number of coupled tasks will change to 11 tasks.

The C.F.s of the most dominant design mode are shown in Table (17).

\begin{tabular}{|c|c|c|c|c|c|c|c|c|c|c|c|c|}
\hline Tasks & No. & 3 & 6 & 7 & 8 & 9 & 10 & 11 & 12 & 13 & 14 & 15 \\
\hline Select Preliminary Configuration Alternative & 3 & 0 & 0 & 0.3 & 0 & 0.3 & 0 & 0.2 & 0 & 0 & 0 & 0 \\
\hline Preliminary Structural Arrangement & 6 & 0 & 0 & 0 & 0 & 0 & 0.1 & 0 & 0 & 0 & 0.3 & 0.1 \\
\hline Prepare for cabin \& Fuselage Design & 7 & 0.2 & 0 & 0 & 0 & 0 & 0 & 0 & 0 & 0 & 0 & 0 \\
\hline Develop Structural Design Conditions & 8 & 0 & 0.2 & 0 & 0 & 0 & 0 & 0 & 0 & 0 & 0 & 0 \\
\hline Integration Propulsion & 9 & 0 & 0 & 0.4 & 0 & 0 & 0 & 0 & 0 & 0 & 0 & 0 \\
\hline Perform Preliminary Weight \& Balance & 10 & 0 & 0 & 0.3 & 0 & 0.4 & 0 & 0 & 0 & 0 & 0.5 & 0 \\
\hline Stability \& Control Analysis & 11 & 0 & 0 & 0 & 0 & 0.5 & 0.7 & 0 & 0 & 0 & 0 & 0 \\
\hline V-n Diagram & 12 & 0 & 0 & 0 & 0.2 & 0 & 0.1 & 0 & 0 & 0.4 & 0 & 0 \\
\hline Internal Load Distributions & 13 & 0 & 0 & 0 & 0.5 & 0 & 0.5 & 0 & 0.3 & 0 & 0 & 0 \\
\hline Structural Analysis & 14 & 0 & 0 & 0 & 0.5 & 0.2 & 0 & 0 & 0.1 & 0.1 & 0 & 0 \\
\hline Preliminary Production Program & 15 & 0 & 0.2 & 0.1 & 0 & 0.1 & 0 & 0 & 0 & 0 & 0.1 & 0 \\
\hline
\end{tabular}

Table 16. The WTM after partitioning and tearing (Fourth case) 


\begin{tabular}{|c|c|c|}
\hline Task Name & Eigenvector Elements & Task No \\
\hline Perform Preliminary Weight \& Balance & 0.300 & 10 \\
\hline Stability \& Control Analysis & 0.407 & 11 \\
\hline V-n Diagram & 0.476 & 12 \\
\hline Internal Load Distributions & 0.573 & 13 \\
\hline
\end{tabular}

Table 17. Controlling feature of the most dominant design mode after tearing in $4^{\text {th }}$ case

Case - 5: Case 5 is very similar to that of Case-4, the only difference being that we will tearout Task 6 instead of Task 4. Again, after the tearing and repartitioning, we obtain the results shown in Table (18). In this case, the number of coupled tasks changes to 10 and the C.F.s of the most dominant design mode can then be represented as in Table (19).

Table (20), Along with Figures 8 through 13, shown a comparison between results of five scenarios. The comparison is particularly useful for understanding WTM's both before and after tearing.

Table-20 Summer of the important results. The second column of this table indicates a coefficient of $S^{-1} u_{0}$ for each case. The third column of the table shows the eigenvalues of the most dominant mode of each case. The fourth column of the table presents the main problems of each case.

\begin{tabular}{|c|c|c|c|c|c|c|c|c|c|c|c|}
\hline Tasks & No. & 3 & 4 & 5 & 7 & 9 & 10 & 11 & 12 & 13 & 14 \\
\hline Select Preliminary Configuration Alternative & 3 & 0 & 0 & 0 & 0.3 & 0.3 & 0 & 0.2 & 0 & 0 & 0 \\
\hline Mathematical Surface Models & 4 & 1 & 0 & 0.4 & 0.2 & 0 & 0 & 0 & 0 & 0 & 0 \\
\hline Aerodynamics Calculation & 5 & 0 & 0.5 & 0 & 0 & 0 & 0 & 0 & 0 & 0 & 0 \\
\hline Prepare for cabin \& Fuselage Design & 7 & 0.2 & 0 & 0 & 0 & 0 & 0 & 0 & 0 & 0 & 0 \\
\hline Integration Propulsion & 9 & 0 & 0 & 0 & 0.4 & 0 & 0 & 0 & 0 & 0 & 0 \\
\hline Perform Preliminary Weight \& Balance & 10 & 0 & 0 & 0 & 0.3 & 0.4 & 0 & 0 & 0 & 0 & 0.5 \\
\hline Stability \& Control Analysis & 11 & 0 & 0 & 0.7 & 0 & 0.5 & 0.7 & 0 & 0 & 0 & 0 \\
\hline V-n Diagram & 12 & 0 & 0 & 0.1 & 0 & 0 & 0.1 & 0 & 0 & 0.4 & 0 \\
\hline Internal Load Distributions & 13 & 0 & 0 & 0 & 0 & 0 & 0.5 & 0 & 0.3 & 0 & 0 \\
\hline Structural Analysis & 14 & 0 & 0 & 0 & 0 & 0.2 & 0 & 0 & 0.1 & 0.1 & 0 \\
\hline
\end{tabular}

Table 18. The WTM after partitioning and tearing (Case 5) 


\begin{tabular}{|c|c|c|}
\hline Task Name & Eigenvector Elements & Task No \\
\hline Mathematical Surface Models & 0.600 & 4 \\
\hline Aerodynamics Calculation & 0.443 & 5 \\
\hline Stability \& Control Analysis & 0.580 & 11 \\
\hline
\end{tabular}

Table 19. Controlling feature of the most dominant design mode after tearing in Case 5

\begin{tabular}{|c|c|c|c|}
\hline Cases $\backslash$ Results & Dominant Mode $S^{-1} u_{0}$ & $\begin{array}{c}\text { Dominant Mode } \\
\text { Eigenvalue }\end{array}$ & $\begin{array}{c}\text { Dominant Mode } \\
\text { Main Problem }\end{array}$ \\
\hline Basic Case & 5.730 & 0.700 & $\begin{array}{l}\text { 1-Structure design \&analysis } \\
\text { 2-Mathematical surface model } \\
\text { 3-Aerodynamic analysis } \\
\text { 4-Stability \&Control Analysis }\end{array}$ \\
\hline Case-1 & 2.280 & 0.480 & 1-Structure analysis \\
\hline Case-2 & 3.490 & 0.530 & 1-Structure analysis \\
\hline Case-3 & 3.510 & 0.540 & 1-Structure analysis \\
\hline Case-4 & 5.430 & 0.570 & $\begin{array}{l}\text { 1-Structure analysis } \\
\text { 2-Weight \& Balance } \\
\text { 3-Stability \& Control }\end{array}$ \\
\hline Case-5 & 4.980 & 0.680 & $\begin{array}{l}\text { 1-Mathematical surface model } \\
\text { 2-Aerodynamic analysis } \\
\text { 3-Stability \&Control Analysis }\end{array}$ \\
\hline
\end{tabular}

Table 20. Important results after implying mentioned five scenarios

Table (20) and Figures 8 through 13 show:

1. The General Aviation airplane examined here contains four coupled disciplines. However, by using the proposed method, it could effectively reduce the number of coupled disciplines from four to three, two or even one. Thus, implementing tearing based on C.F.s will always lead to a smaller design problem (with less discipline and less coupled parts) (Table-20).

2. The number of C.F.s and the weight of each are minimized in Case-1(Figures-9, 10).

3. FromTable-20 and Figures 8 through 13 , we can observe a reduction in the dynamic order of system: that is, the suggested criterion effectively leads to a better convergence speed. Comparing the $1^{\text {st }}$ case to the $5^{\text {th }}$ case one can conclude that Case 1 is more efficient as far as speed of convergence is concerned. In this case, we also observe a 
reduction in the coupled part of the design process. This is mainly because Tasks 11, 4, and 6, which have the highest influence on the most dominant mode, are torn. On the contrary, Case 5 offers the least improvement in all the discussed area. In Case 5 only Task 6 is torn, which influences on the most dominant mode $12 \%$ less than that of Task 11. (Table-4)

4. It can also be observed that Case-3 offers the best case scenario only if we are restricted to a certain number of tear-out tasks. That is to say that "Coupled Part Reduction" (CPR) is relatively better. We don't see a big difference as far as other criterion is concerned. Case- 3 offers $50 \%$ and $44 \%$ better CPR than that of Cases 1 and 2 (Fig-11).

5. The total work decreases in all mentioned cases. Case- 1 has the most improvement, by $85 \%$, while Case- 5 exhibits minimal improvement, by a factor $32 \%$ (Fig-12).

6. The rank of the design process dominant mode also decrease after reduction of the dynamic order of the G.A. airplane design process. It can be observed that Case- 5 has the minimum ranking improvement (Fig-13). Dynamic order reduction of the design process was performed by the tearing-out of Task 6 only, which influences on the most dominant mode is minimum (relative to Tasks 11 and 4).

This example shows why we need to have a systematic approach, as presented here, in the implementation of "dynamic order reduction" or "tearing".

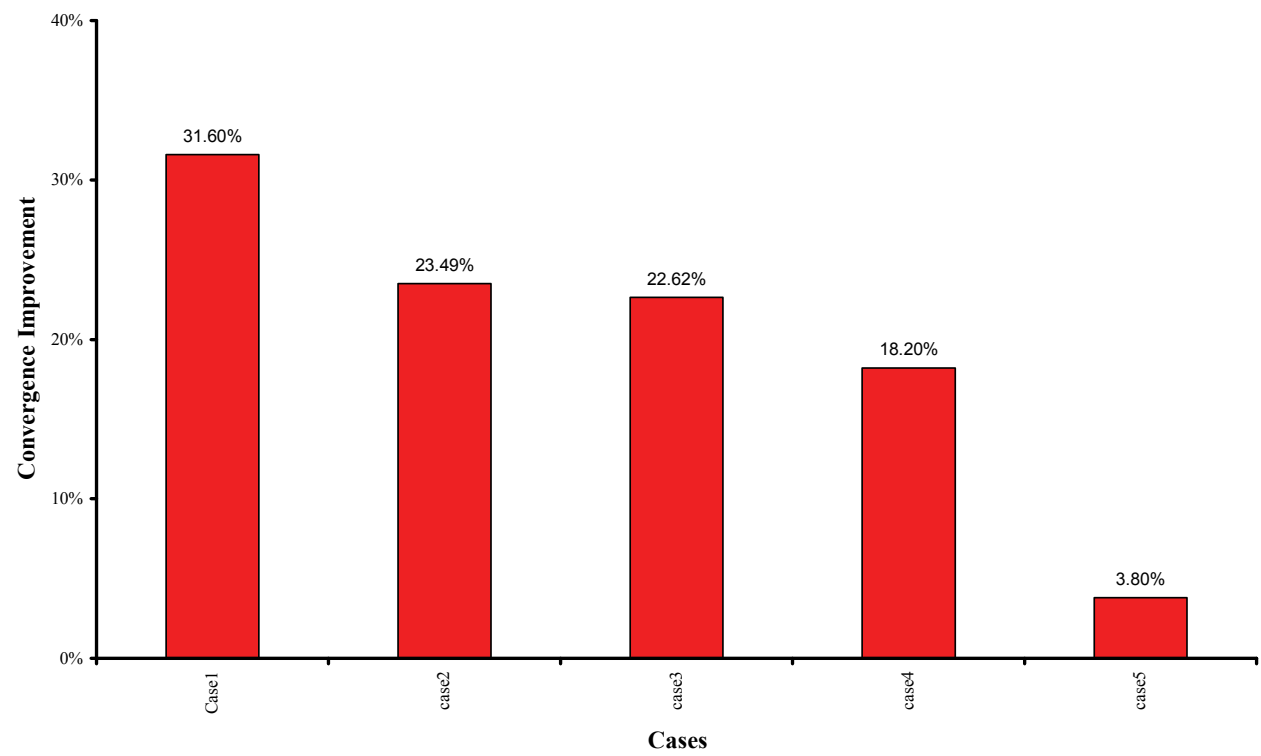

Fig. 8. Convergence Improvement in each scenario 


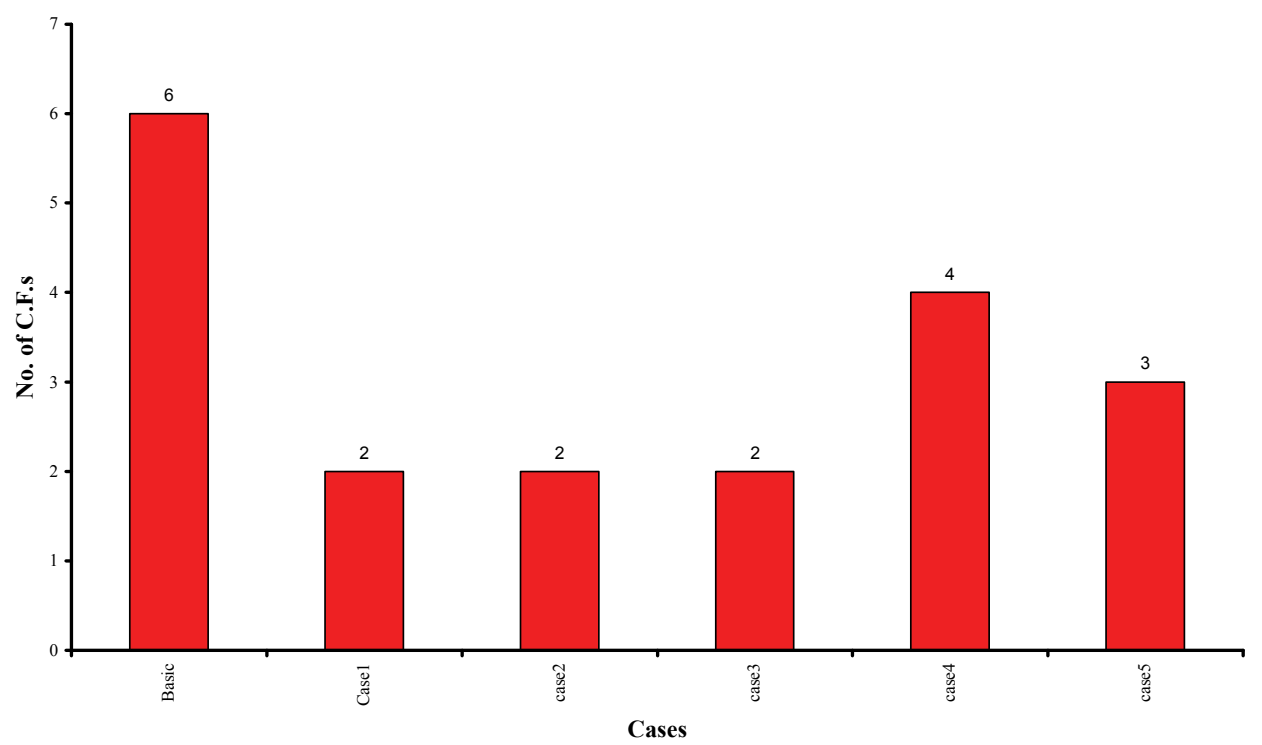

Fig. 9. No. of C.F.s in basic WTM and in each scenario.

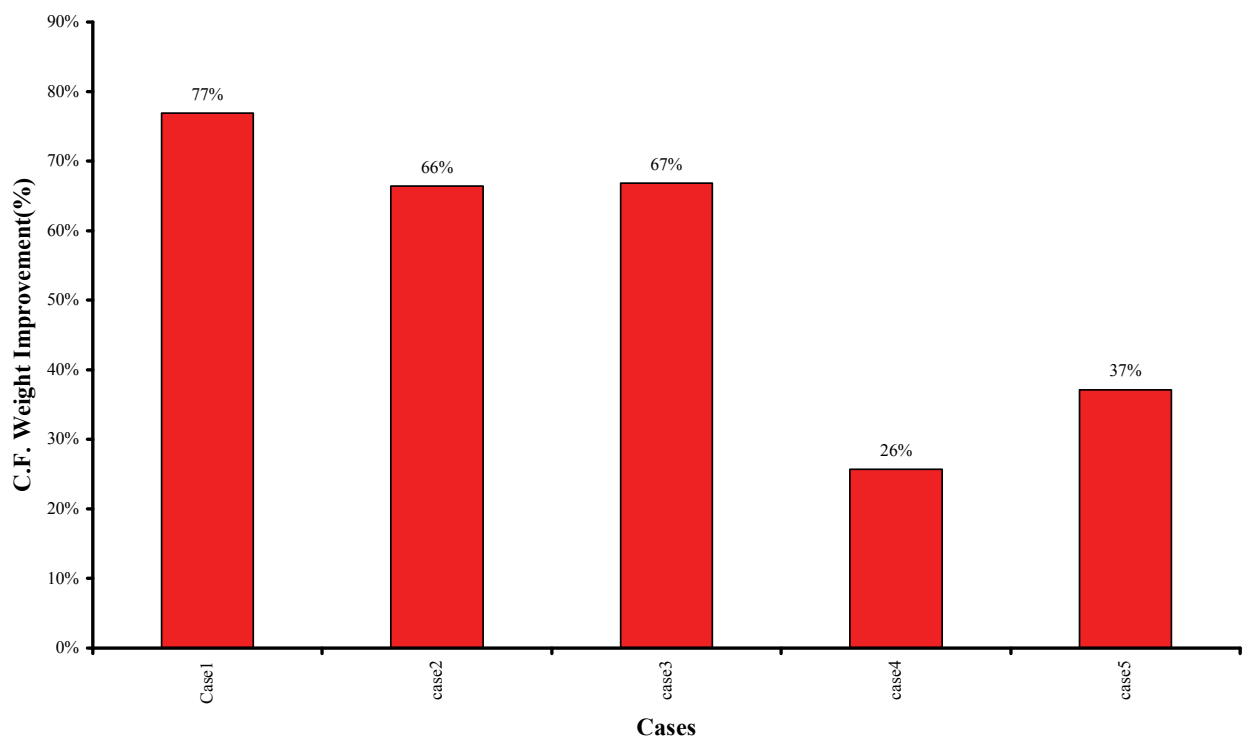

Fig. 10. Improvements in C.F.s Weight in each scenario 


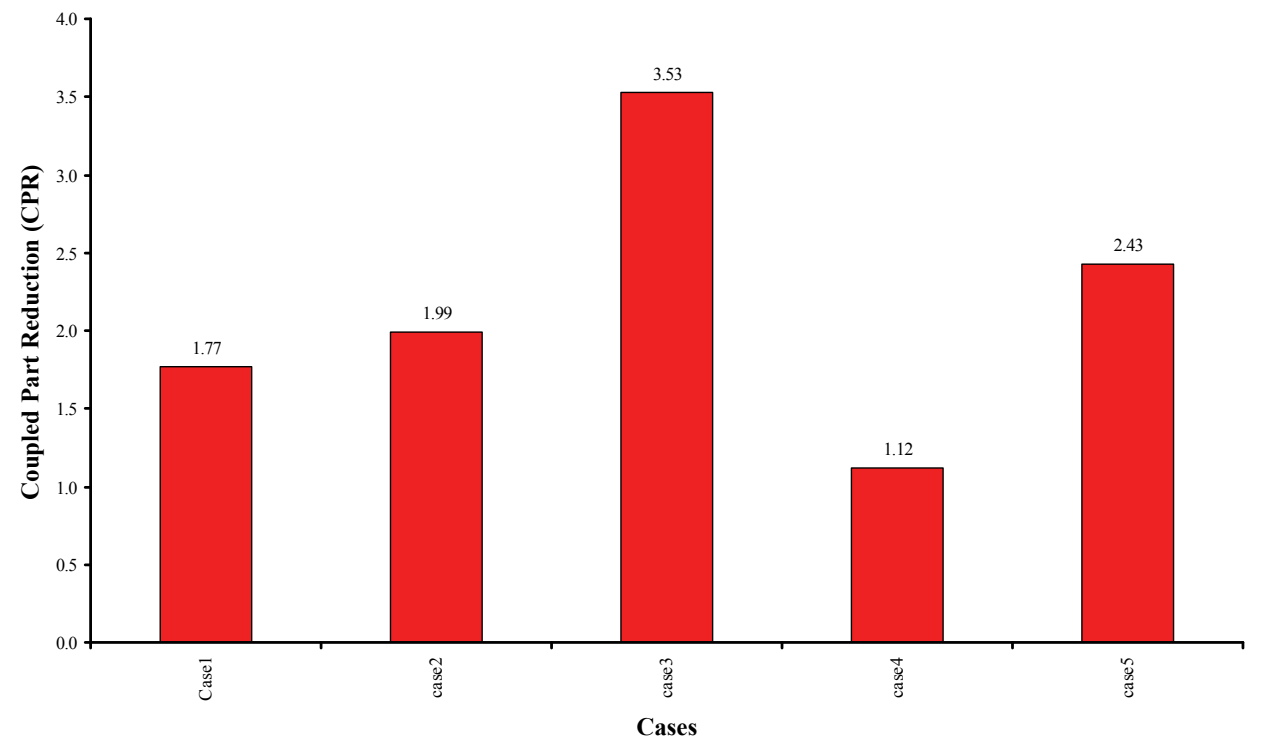

Fig. 11. Coupled Part Reduction (CPR) in each scenario

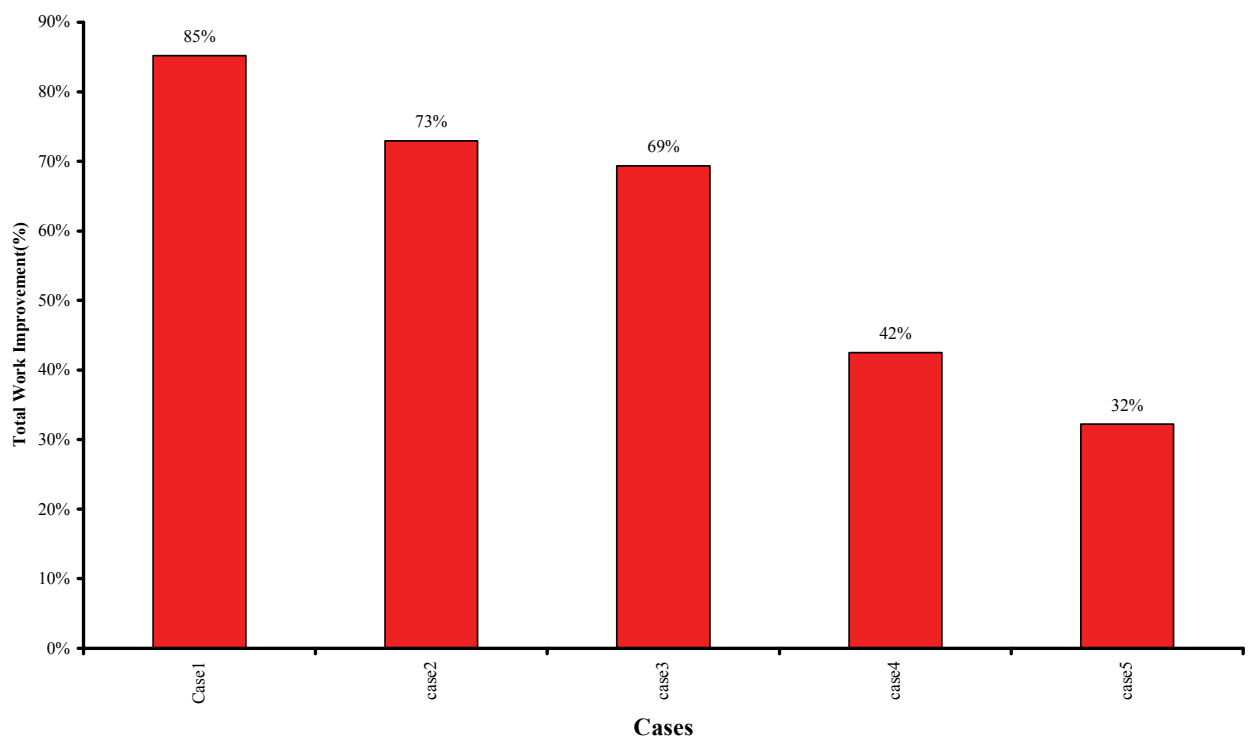

Fig. 12. Total work Improvements in each scenario 


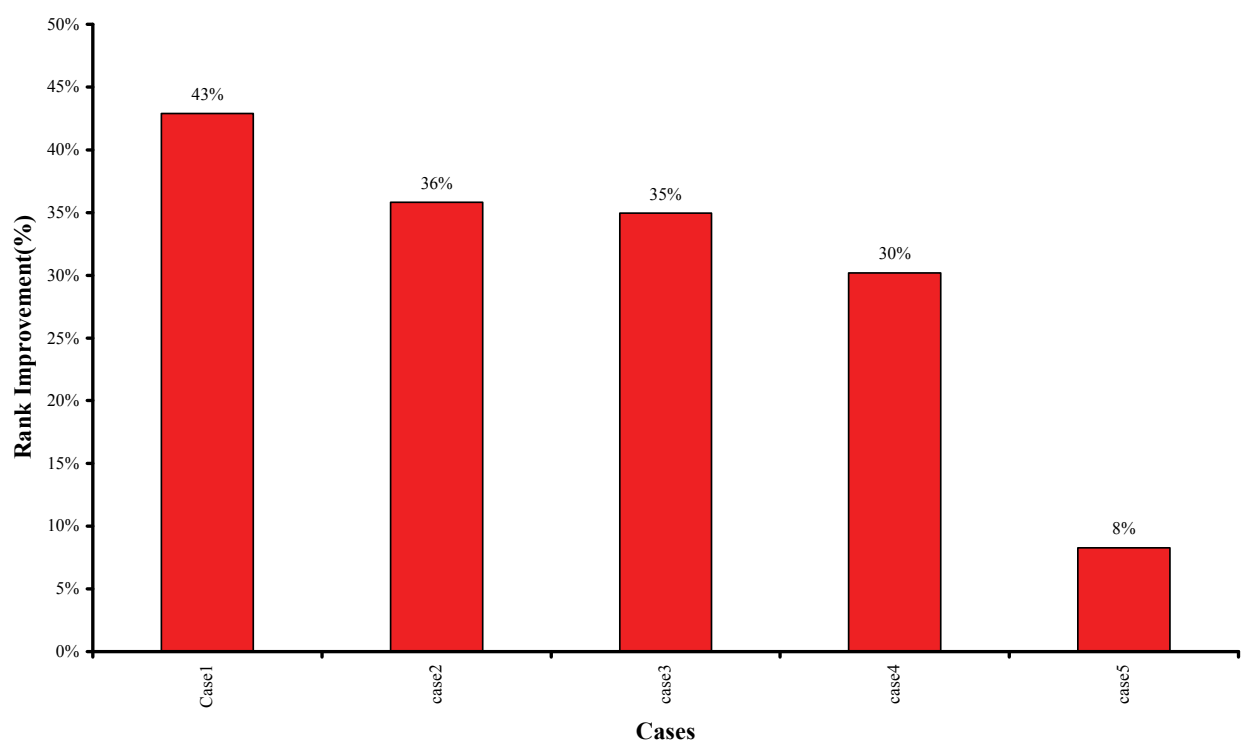

Fig. 13. Rank Improvement in each scenario

\section{Discussion}

This chapter presents a systematic approach to re-organize a complex design process to a more manageable one based on its analogy to dynamic systems. The proposed method is most useful where there are some limitations on time and budget as well as background experience. This new technique could also serve as a component of the Integrated Airframe Design (IAD) to systematically reduce the design cycle time. The current approach, being simple in nature, can easily be used to prevent additional expenses incurred by employing more elaborate management techniques.

The most interesting feature of this method relates to the fact that it enables engineers to have a management tool of their own to help them better understand the effects of their decisions while dealing with the information cycles.

This approach could also be used as a means of evaluating the possible effects of items, such as: (1) international cooperation and (2) sub-contracting in very big projects. Figures 5, 6 and 7 show how coupled parts of a design process can be converted into modular processes via the proposed technique.

In fact, complex projects such as the International Space Station (ISS) or "Traveling to Mars" are good examples of possible re-evaluations via the current technique. In such projects, proper breaking of information cycles is essential to the success of the project, as the budget constraints are a dominant feature of such projects.

Current chapter could also be used to reorganize engineers to improve the overall organizational behavior in terms of "time of response". Through analyzing the project WTM, proper arrangements for engineers with different levels of skills, knowledge, and experience can also be found. This approach provides a systematic way to increase the responsiveness of an organization by arrangement engineers based on their skills. 
Regardless to all the benefits it must be note that there are some legitimate questions regarding the validity of such techniques. In fact, the major concern in applying crisp mathematical procedure in real world applications is the fact that the real world comes with a tremendous amount of details which are not normally modeled. Thus, there is always a concern regarding the influence of "tearing" on the "Quality of the design work".

Fundamentally, by imposing time and budget constraints, one can not expect to have any increase in the quality of the design work. In general, we do not desire to jeopardize the integrity of the design work through imposing such time and budget constraints. Therefore, it would be logical to expect the same while applying the discussed "tearing". Fortunately, using approaches such as "Robust Design" could decrease this sensitivity and, in any case, mathematically guarantee the integrity of the project. The idea, therefore, demands further investigation which has been the subject of the authors separate research. Studies conducted so far show that it needs to somehow correlate and balance the "convergence speed of iterations" and the "quality of the design work".

Another interesting outcome of this method relates to projects, where the entries of the eigenvectors are numerically close to one another. This happens when all experts give the same weight factor to their own work. In such cases, the manager still needs to have a clear understanding of the relative importance of either working groups. One can easily conduct a sensitivity analysis on dependency amount the tasks, and has access to tools such as described in this chapter.

In this study, we consider only the effect of C.F.s on iteration convergence speed. However, it could also be add effect of the number of inputs and outputs of each C.F. those are candidate to the tear-out process.

It is well noted that in some cases, due to the changes in dependency amount the tasks, the assumption of having a time independent work transformation matrix (WTM) will no longer be applicable. In such cases, one could model the complexity amount disciplines to minimize the information cycles inside the organization. Nevertheless, we continually need to exercise caution as to whether the assumptions regarding the linear dependency coefficients is reasonable.

The method described in this chapter aim to open a new window from which chief engineers can improve their management skills. These tools should not be treated as formulas that are expected to deliver crisp results. Rather, they should be seen as strong tools that can provide systematic alternatives to manage a design process.

Although mathematical methods are straightforward and easy to comprehend, there would, however, always be some concern for their suitability in complex socio-economical processes such as cases of multidisciplinary design works. This concern can only be investigated by the proper implementations of the discussed method in real engineering works. Nevertheless, the proposed method stems from solid mathematical background and any possible shortcomings are expected to be dealt with reasonably straightforward.

\section{References}

AGARD-R-814,"Integrated Airframe Design Technology", 8-9 May, 1996.

Austin S. A, Baldwin A. N., Li B., Waskett P. R.," Analytical Design Planning Technique (ADePT)", Design Studies, Vol. 20, No. 3, April 1999. 
Browning Tyson R. "Modeling and Analysis Cost, Schedule, and Performance in complex System Product Development" , Ph.D. Thesis, MIT, December 1998.

B. Soltanmohammad "Design Process Control Based on Dynamic System Characteristics ", Ph.D. Thesis, Sharif University, Tehran - IRAN, Agust 2006.

Clark, Kim B. and Steven C. Wheelwright (1993b) Managing New Product and Process Development, New York:Free Press.

David G. Ullman,"The Mechanical Design Process", McGraw-Hill, 2003.

Eisenhardt, Kathleen M. and Behnam N. Tabrizi (1995) "Accelerating Adaptive Processes: Product Innovation in the Global Computer Industry" Administrative Science Quarterly 40(Mar.): 84-110.

Eppinger,S., Whitney, D., Smith, R. and Gebala, D., "A Model - Based Method for Organizing Tasks in Product Development", Research in Engineering Design,6,PP. 1-13,1994.

Kurt Hacker. And Kemper Lewis, "Using Robust Design Techniques To Model The Effects Of Multiple Decision Makers In A Design Process." ASME Design Engineering Technical Conferences, Atlanta, Georgia,1998.

Kusiak, A. and Wang, J., "Efficient organizing of design activities", International Journal of Production Research, 31,735-769, 1993.

Minc Henryk, "Nonnegative Matrices", John Wiley \& Sons, 1988

NASA/CR-2001-210658, William Spitz, Richard Golaszewski, Frank Berardino, "Development Cycle time simulation for civil aircraft", Gellman Research Associates, Inc., Jenkintown, Pennsylvania, 2001.

Nam P. Suh,"A Theory of Complexity and Applications", 2003.

NSF Strategic Planning Workshop Final Report" Research Opportunities in Engineering Design", April 1996.

Pahl G. and Beitz W.,"Engineering Design: A Systematic Approach", Springer - Verlag London Limited, 1996.

Robert P. Smith, Steven D. Eppinger." Identifying Controlling Features of Engineering Design Iteration", Management Science, Vol. 43, No. 3, March 1997.

Robert P. Smith, "Development and Verification of Engineering Design Iteration Models," Ph.D. Thesis, MIT Sloan School of Management, Cambridge, MA, August 1992.

Rogers, J., “A knowledge - based tool for multilevel decomposition of complex design problem", NASA TP 2903, may 1989.

Shearer, Murphy, Richradson, "Introduction to System Dynamics", Addison - Wesley, 1971

Soo-Haeng Cho, Eppinger. S., "Product Development Process Modeling Using Advance Simulation", ASME Design Engineering Technical Conferences and Computer and Information in Engineering Conference, September 2001.

Steward, D., “The Design Structure System: A Method for Managing the Design of Complex Systems", IEEE Transactions on Engineering Management, EM -28, 1981.

Steward, D.," System Analysis and Management: Structure, Strategy, and Design", New York: Petrocelli Books, 1981.

Yassine A., "An Introduction to Modeling and Analyzing Complex Product Development Processes Using the Design Structure Matrix (DSM) Method", Product Development Research Laboratory. 
Yassine, A., Falkenburg, D., Chelst, K. “Engineering Design Management: an Information Structure Approach", International Journal of Production Research, Vol. 37, No. 13, 1999.

Wei Chen and Kemper Lewis, "A Robust Design Approach for Achieving Flexibility in Multidisciplinary Design", AIAA Journal, 1999. 


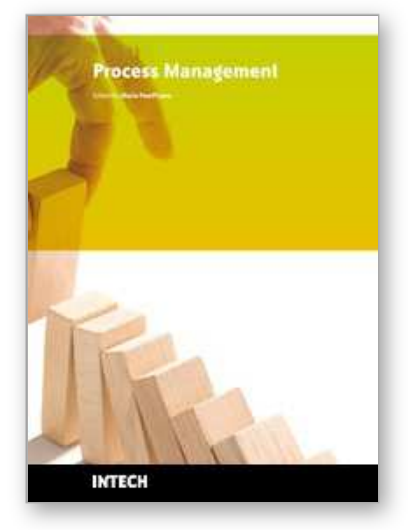

\author{
Process Management \\ Edited by Maria Pomffyova
}

ISBN 978-953-307-085-8

Hard cover, 338 pages

Publisher InTech

Published online 01, April, 2010

Published in print edition April, 2010

The content of the book has been structured into four technical research sections with total of 18 chapters written by well recognized researchers worldwide. These sections are: 1. process and performance management and their measurement methods, 2. management of manufacturing processes with the aim to be quickly adaptable after real situation demands and their control, 3. quality management information and communication systems, their integration and risk management, 4. management processes of healthcare and water, construction and demolition waste problems and integration of environmental processes into management decisions.

\title{
How to reference
}

In order to correctly reference this scholarly work, feel free to copy and paste the following:

Bahram, Soltanmohammad (2010). Design Cycle Period Management, Process Management, Maria Pomffyova (Ed.), ISBN: 978-953-307-085-8, InTech, Available from:

http://www.intechopen.com/books/process-management/design-cycle-period-management

\section{INTECH}

open science | open minds

\section{InTech Europe}

University Campus STeP Ri

Slavka Krautzeka 83/A

51000 Rijeka, Croatia

Phone: +385 (51) 770447

Fax: +385 (51) 686166

www.intechopen.com

\section{InTech China}

Unit 405, Office Block, Hotel Equatorial Shanghai

No.65, Yan An Road (West), Shanghai, 200040, China

中国上海市延安西路65号上海国际贵都大饭店办公楼 405 单元

Phone: +86-21-62489820

Fax: +86-21-62489821 
(C) 2010 The Author(s). Licensee IntechOpen. This chapter is distributed under the terms of the Creative Commons Attribution-NonCommercialShareAlike-3.0 License, which permits use, distribution and reproduction for non-commercial purposes, provided the original is properly cited and derivative works building on this content are distributed under the same license. 